\title{
Multi-Agent Simulation in the Inter-Organizational Trust Model and Knowledge Sharing in the Automotive Industry
}

\author{
Afrin Fauzya Rizana ${ }^{a *}$, Fadillah Ramadhan ${ }^{b}$ \\ a Industrial Engineering Department, Universitas Telkom, Indonesia \\ Jl. Telekomunikasi No 1 Bandung, Indonesia \\ b Industrial Engineering Department, Institut Teknologi Nasional, Indonesia \\ Jl PHH Mustofa No. 23 Bandung, Indonesia \\ * Corresponding author: afrinfauzya@telkomuniversity.ac.id
}

\section{ARTICLE INFO}

Article history

Received January 26, 2019

Revised April 3, 2019

Accepted August 18, 2019

Available Online August 31, 2019

\section{Keywords}

Inter-organizational

Knowledge Sharing

Multi-agent

Simulation

Trust

\begin{abstract}
Two organizations can share knowledge to determine the success of their collaboration. Effectiveness in knowledge sharing affects organizational performance and trust between organizations. This study aims to identify the implementation of multi-agent simulations to increase trust in sharing knowledge between organizations. A multi-agent simulation approach was used in this study. The research model was adopted from previous research. Several hypotheses and path coefficients were tested in simulation models. This study showed that multiagent simulation is suitable as a problem-solving method for complex issues such as knowledge sharing. In addition, this study identified individual factors such as likability and expertise in the success of knowledge sharing between organizations.
\end{abstract}

\section{Introduction}

The automotive industry is the sector that is responsible for product development. The automotive industry produces quality products. The selection of materials of the goods has strong influences. The supplier is one of the critical factors in the production line to meet the requirements of the component [1]. Time, quality, and quantity consistency can be used as a guide when measuring the performance of suppliers [2]. Through collaboration, the industry can combine the resources, skills, and knowledge of the supplier within the company. Furthermore, collaboration encourages good quality products [3]. Collaboration is expected to reduce transaction costs, improve productivity, increase profitability, and enhance the company's competitive advantage [4]. When part of the process of collaboration, companies can share the expertise they have. Knowledge sharing can help in problem-solving, designing products, improving manufacturing capability, and developing product quality [5]. Knowledge sharing within organizations 
helps companies develop new skills, develop best practices, and enhance work performance [6].

Several previous studies have discussed issues that affect the sharing of interorganizational knowledge. Chen, Yin, and Len [7] concluded that inter-organizational trust in collaboration is a critical aspect of inter-organizational knowledge sharing. The high level of trust leads the organization to share helpful information with other organizations [8]. Furthermore, Ramadan and Samadhi [9] claimed that effective interorganizational knowledge sharing is influenced by organizational aspects, personal aspects, and aspects of trust. Based on these studies, trust is a critical factor in the interorganizational knowledge-sharing process. Trust is defined as the belief in a partner to achieve a positive outcome and not take action that negatively impacts. Although the model is pretty comprehensive, previous studies only use a statistical approach to explain the relationship between variables. The knowledge-sharing process is a dynamic process that involves interaction between people, systems, and the environment [10] [11]. Therefore, the knowledge sharing process is not sufficiently represented in the statistical models [10] [11].

As an alternative to the statistical approach, some previous researchers used a multi-agent approach to describe the knowledge sharing process [12] [11] [10]. A multiagent approach can describe relationships between individuals involved in the knowledge-sharing process [10]. However, in the context of inter-organizational knowledge sharing, no work incorporates the idea of a multi-agent. In interorganizational knowledge sharing, companies can try to protect their knowledge by limiting the knowledge-sharing process. Knowledge sharing between the business and its partners can improve its partners' competitive advantage [13]. Therefore, this study attempts to identify the use of multi-agent simulation to increase inter-organizational trust and knowledge sharing between manufacturers and suppliers in the automotive industry.

This study consists of four parts: introduction, methods of research, results, and discussion, as well as conclusions. The Introduction section discusses the background of this work. The research method addresses the approaches used in this study to solve problems. The results and discussion are discussed regarding the results of the simulation scenario. Finally, the final section is described in the summary of findings and suggestions for further study.

\section{Methods}

\subsection{Research Design}

The research design of the work is shown in Fig. 1. There were five major stages of this research. The first was the identification of conceptual models showing the structural models of the hypotheses. Second, the design of simulation models is focused on predictions and the flow of actual conditions that exist in the case under review. Third, implement an agent-based simulation software model in NetLogo. Fourth, the validation of the model to ensure that the model can be used to predict the system. Sixth, the generation to analyze and obtain findings related to the combination of inputs.

\subsection{Conceptual Model of Inter-Organizational Knowledge Sharing}

The conceptual model of this study used a model of inter-organizational knowledge sharing in the automotive industry developed by Ramadhan \& Samadhi [9]. The conceptual model is shown in Fig. 2. 


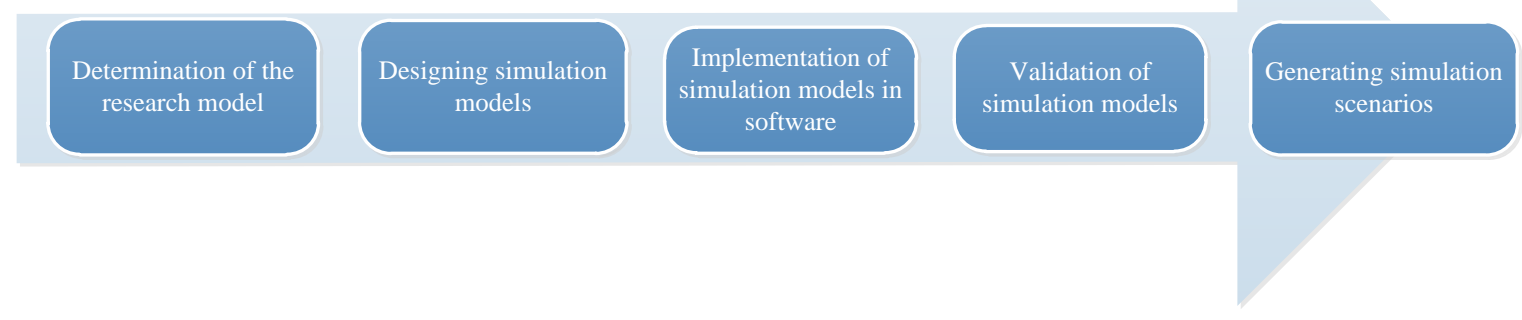

Fig. 1. Research Method

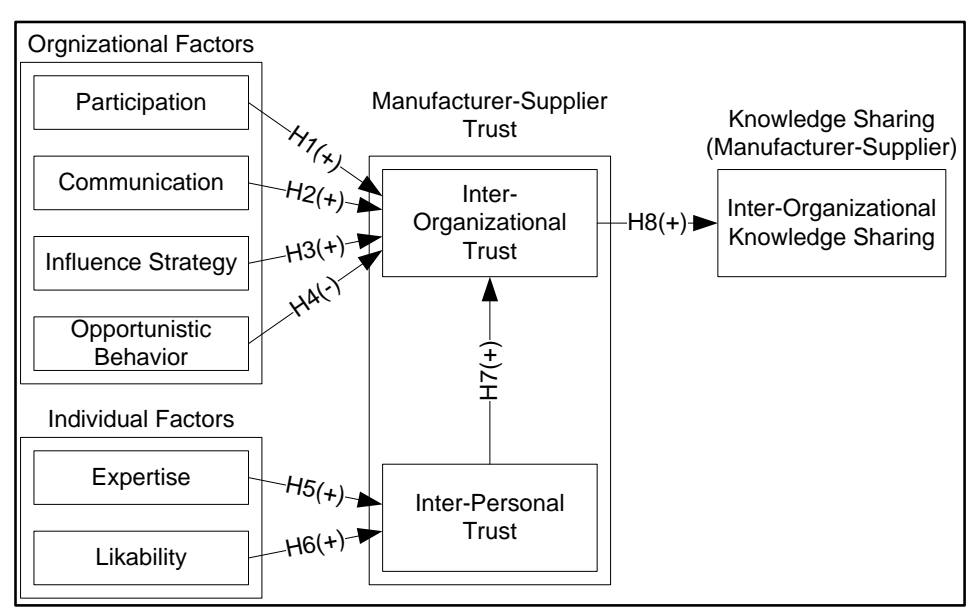

Fig. 2. Conceptual Model of Inter-Organizational Knowledge Sharing

Participation is defined as a measure of the extent of common commercial goals [9]. It was reviewed via supplier involvement in generating ideas, decision-making, and planning and goal setting [9]. The higher participation was carried out by partners and the higher trust between organizations. Communication can increase reliance on companies [13]. In this study, communication is the process of sharing information between the manufacturer and the supplier [14]. Influence strategy is a strategic mechanism to encourage organizational behavior in achieving organizational goals [7]. In this study, influence strategy means a strategy carried out by manufacturers or suppliers to improve coordination. Potential opportunistic behavior can occur in cooperation between companies [15]. In relationships between companies, the partner companies become opportunistic when organizational behavior is inconsistent and detrimental to the other companies [16]. In this research, opportunistic behavior is behavior that selfish and detrimental to other companies.

Furthermore, skill is the capabilities of each producer or supplier in building trust between companies [16]. Interactions that occur on manufacturers and suppliers of cooperation include buying and selling, technology, or upgrading competence. Based on these explanations, expertise can enhance personal confidence. Likability is defined as a manufacturer and supplier assessment related to friendliness, openness, and mutual personal delight [9]. A person's likability influences the personality of the automotive industry, cooperation, and interaction between individuals. 
Inter-personal reliance is a measure of individual confidence in employees from the buyer and supplier side [17]. Inter-personal reliance can affect inter-company dependence rationally at the organizational level [17]. Ramadan \& Samadhi [9] explains that inter-personal confidence can affect inter-organizational reliance On the individual level. Reliance is an important aspect that facilitates business interaction and knowledge sharing between companies [7] [18]. Inter-organizational dependence is an essential factor that can increase inter-organizational knowledge sharing.

Based on the previous research, this study creates a hypothesis that assumes relationships between variables. The hypotheses were then verified by the partial least square model (SEM-PLS). The Hypotheses are presented in Table 1.

Table 1. Hypothesis

Hypothesis (H)

H1: Participation has a positive influence on inter-organizational reliance.

$\mathrm{H} 2$ : Communication has a positive influence on inter-organizational reliance.

H3: Influence strategy has a positive influence on inter-organizational reliance.

H4: Opportunistic behavior has a negative influence on inter-organizational reliance.

H5: Expertise has a positive influence on interpersonal trust.

H6: Likability has a positive influence on interpersonal trust.

H7: Inter-personal trust has a positive influence on inter-organizational trust.

H8: Inter-organizational trust has a positive influence on inter-organizational knowledge sharing.

\subsection{Data collection}

Data were collected by a questionnaire. Data were obtained from manufacturers that have suppliers. The sampling method used purposive sampling. The purpose was to ensure the compatibility of questionnaire respondents with existing content. Based on questionnaires, data was collected around 120 responses, and only 97 data can be processed.

\subsection{Determination of Input-Output Simulation}

Inter-organizational Knowledge Sharing (IKS) was the result of the study. IKS has a scale from 0 to 100 . 0 was a low value, and 100 was a very high value. Individuallevel was the main problem of this study. Two significant variables that influence producer and supplier dependency were skills and likability. Those two factors act as dependent variables. The value of the two elements was combined with independent variables at the organizational level. Independent variables were participation, communication, influence strategy, and opportunistic behavior.

\subsection{Determination of Agent, Attributes, and Behavior}

Manufacturers and suppliers in the automotive industry were objects in knowledge-sharing activities. Individual company workers interact with their supplier employees. Thus, there were two types of agents in individual producers and their suppliers. Both of the agents interacted more with the producer agent. Factors that affect the process of sharing knowledge between the two types can be identified. Agent attributes and behavior of agents are shown in Table 2. Attributes were assigned to each agent of skill and likability. Each agent has a different identity (ID). The agent's behavior in this process is sending and receiving knowledge. 
Table 2. Agent, Attribute, and Agent Behavior

$\begin{array}{lll}\text { Agent Type } & \text { Attribute } & \text { Agent Behavior } \\ \text { Individual Manufacturer } & \text { ID, Expertise, Likability, } & \text { Send and receive knowledge } \\ & \text { IPT } & \\ \text { Individual Supplier } & \text { ID, Expertise, Likability, } & \text { Send and receive knowledge } \\ & \text { IPT }\end{array}$

\subsection{Design of Multi-agent Simulation Model}

Multi-agent simulation is a simulation model that emphasizes individual agents as sub-components. Individual agents interact with each other to influence the whole system [19]. Previous research has shown that multi-agent methods can solve complex system problems [20] [11] [21] [12] [22]. There were two levels of analysis in the simulation model: the individual and organizational levels. The organizational level directly influenced inter-organizational trust (IOT). Producers and suppliers' influence were the factors at the organizational level. In this model, producers can act as senders of knowledge. Suppliers act as receivers and senders of expertise. Thus, the IoT value can be average. Individual-level factors are the main focus of this simulation model because interactions between agents modeled the individual level.

Moreover, interactions between agents were identified to determine the effect of individual-level on IOT. It affected knowledge-sharing between organizations (IKS). Furthermore, the simulation process of flow was designed. The simulation begins with the initialization of the time and value of organizational characteristics (participation, communication, influence strategies, and opportunistic behavior). This value is an independent variable parameter. It is a characteristic of producers and supplier companies. A simulation flow diagram is presented in Fig. 3.

\subsection{Simulation Model Validation}

The model validation process was divided into two steps. The first step was model validation, and the second was extreme validation (replication). Model validation aimed to measure model sensitivity by a random process. Excessive validity was implemented to examine the output value.

\section{Results and Discussion}

\subsection{Results Hypothesis and Path Coefficient}

The hypothesis test used the SEM-PLS method. The results of testing the hypothesis are shown in Table 3. Based on the path coefficient values in Table 3, it can be written as:

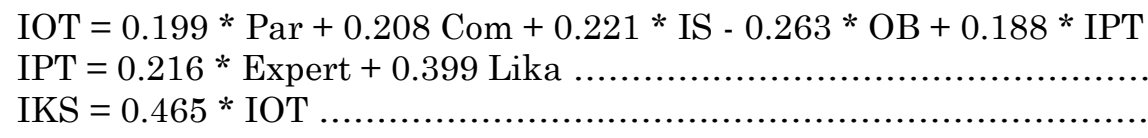

IOT: Inter-Organizational Trust; Par: Participation; Com: Communication; IS: Influence Strategy; OB: Opportunistic Behavior; IPT: Inter-Personal Trust; Expert: Expertise; Lika: Likability; IKS: Inter-Organizational Knowledge Sharing. 
Table 3. Acceptance hypothesis

\begin{tabular}{ccll}
\hline Hypothesis & Path Coefficient & P-Value & Conclusion \\
\hline H1 & 0.199 & 0.032 & Accepted \\
H2 & 0.208 & 0.023 & Accepted \\
H3 & 0.221 & 0.023 & Accepted \\
H4 & -0.263 & 0.004 & Accepted \\
H5 & 0.216 & 0.030 & Accepted \\
H6 & 0.399 & 0.004 & Accepted \\
H7 & 0.188 & 0.011 & Accepted \\
H8 & 0.465 & 0.000 & Accepted \\
\hline
\end{tabular}

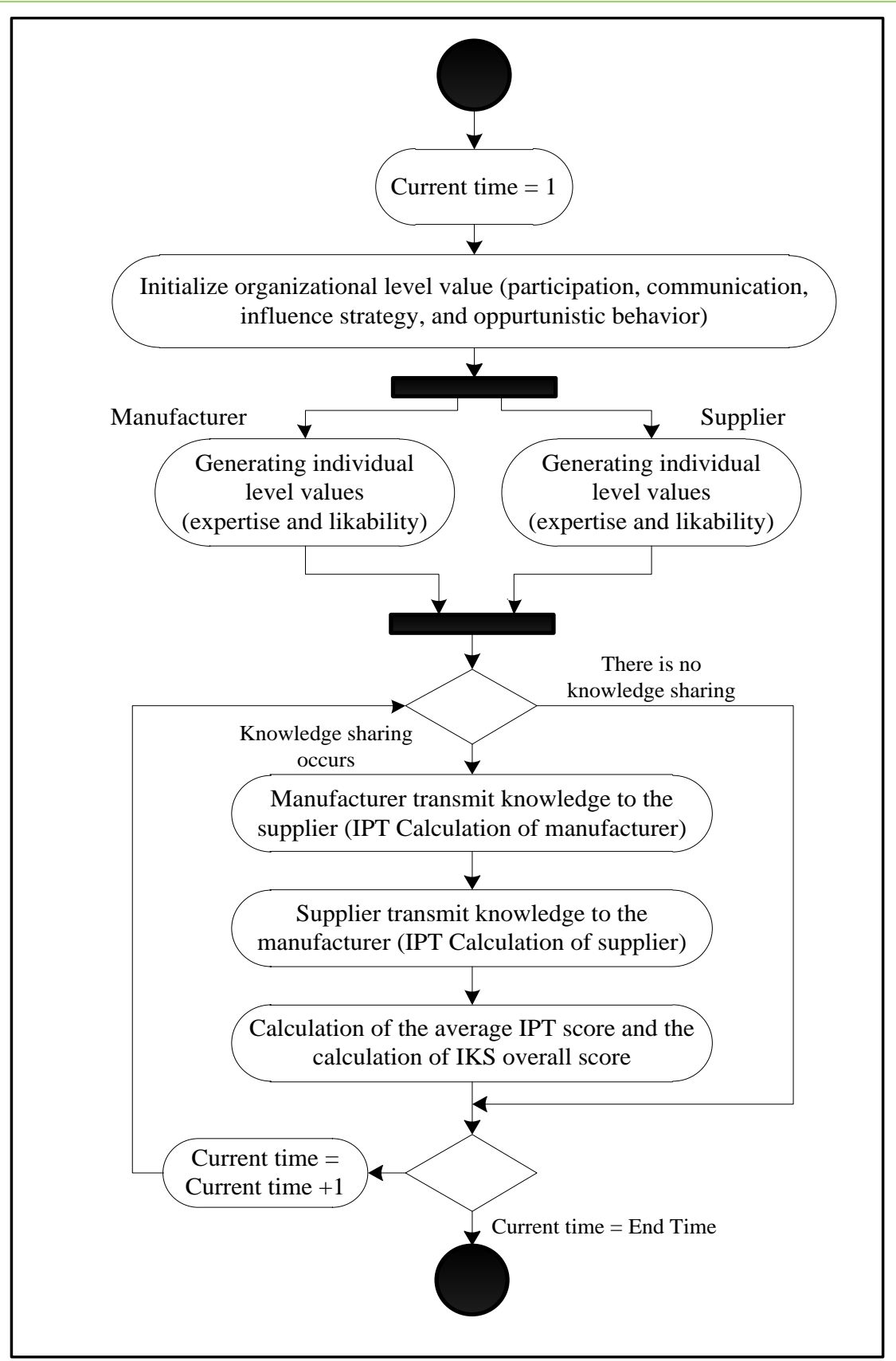

Fig. 3. Flow Simulation Model of Knowledge Sharing between Agent 


\subsection{Model Validation Results}

The results of model replication are shown in Fig. 4. Based on Fig. 4, there are no values that exceed the upper bound and lower bound. Replication is implemented on several system characteristics. The characteristics of the system are the number of suppliers in manufacturing agents. There is low, medium, and large scale. It is concluded that the random process in this simulation model is good and did not include a sensitive simulation model.

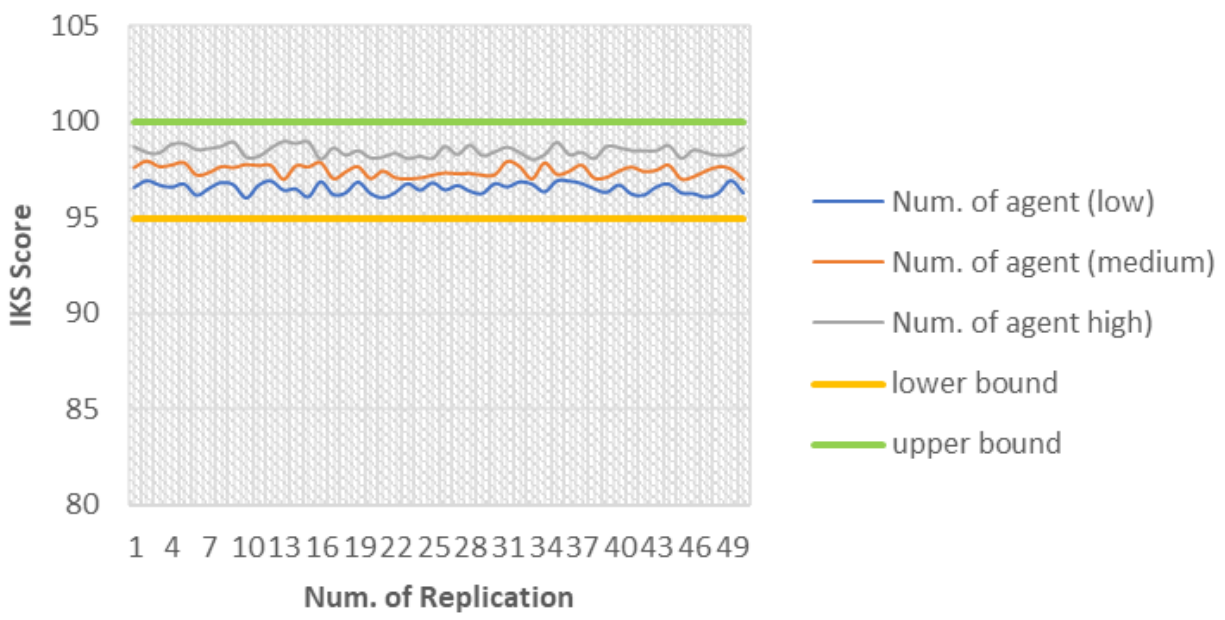

Fig. 4. Replication Output

The results of extreme validation are presented in Table 4. It explains that the less the value of organizational level (participation, communication, influence strategy, and opportunistic behavior) and individual level (expertise and likability). Therefore, the amount of IKS can be smaller. These results prove that the tone of the simulation model is logically by actual system conditions. Thus, it concludes that the simulation model is overall valid and can create simulation scenarios.

Table 4. Extreme Validity Simulation Model

$\begin{array}{ccc}\text { Organization Level } & \text { Individual Level } & \text { IKS Score } \\ \text { Score } & \text { Score } & \\ \text { Low } & \text { Low } & 0.50 \\ \text { Low } & \text { High } & 13.85 \\ \text { High } & \text { Low } & 86.43 \\ \text { High } & \text { High } & 99.79\end{array}$

\subsection{Multi-agent Simulation Results}

The main focus of this study is to study the effect of individual characteristics (expertise and likability) in increasing inter-organizational knowledge sharing on the relationship between manufacturers and suppliers. Details about the scenarios generated are shown in Table 5.

In all scenarios, it makes several possibilities for individual characteristics in making the process of sharing knowledge. The scenario results are shown in Table 6. It found that collaborating organizations have low organizational value. The level of skill and likability of each interaction did not help increase the knowledge-sharing between 
organizations. It is consistent with the results of several previous studies [23] [24]. According to Zhang and Jiang [24], organizational characteristics influenced knowledge sharing. The aspects of organizational culture determined the effectiveness of sharing knowledge carried out by an individual [23] [25] [26].

Table 5. Research Scenarios

\begin{tabular}{|c|c|c|}
\hline Scenario & Explanation & \\
\hline 1 & $\begin{array}{l}\text { The Company does not have policies that } \\
\text { support a culture of knowledge sharing in the } \\
\text { company or inter-company. }\end{array}$ & $\begin{array}{l}\text { The parameter values for } \\
\text { participation, communication, } \\
\text { influence strategy, and } \\
\text { opportunistic behavior are low }\end{array}$ \\
\hline 2 & $\begin{array}{l}\text { The company began to aware and } \\
\text { implemented a knowledge-sharing culture } \\
\text { among companies }\end{array}$ & $\begin{array}{l}\text { The parameters of participation, } \\
\text { communication, influence } \\
\text { strategy, and opportunistic } \\
\text { behavior are moderate }\end{array}$ \\
\hline 3 & $\begin{array}{l}\text { The company implements a culture of } \\
\text { knowledge sharing between companies well } \\
\text { and has policies related to knowledge sharing }\end{array}$ & $\begin{array}{l}\text { The parameters of participation, } \\
\text { communication, influence } \\
\text { strategy, and opportunistic } \\
\text { behavior are high }\end{array}$ \\
\hline
\end{tabular}

Table 6. Results from Scenarios

\begin{tabular}{ccccc}
\hline \multirow{2}{*}{ Expertise } & Likability & \multicolumn{3}{c}{ IKS Score } \\
\cline { 3 - 5 } & & Scenario 1 & Scenario 2 & Scenario 3 \\
\hline Low & Low & 0.50 & 51.97 & 86.43 \\
Low & Medium & 4.83 & 56.30 & 90.77 \\
Low & High & 9.16 & 60.63 & 95.1 \\
Medium & Low & 2.84 & 54.31 & 88.78 \\
Medium & Medium & 7.17 & 58.64 & 93.11 \\
Medium & High & 11.5 & 62.98 & 97.44 \\
High & Low & 5.12 & 56.66 & 91.12 \\
High & Medium & 9.52 & 60.99 & 95.46 \\
High & High & 13.86 & 65.32 & 99.80
\end{tabular}

Based on the results of scenario 2, the organizational factor value is moderate. The individual factors of each manufacturer and supplier employe are sufficient to increase inter-organizational knowledge sharing. The results from scenario 3 show that organizational value factors are very high, although individual factors are low. Besides, a knowledge-sharing culture still has good results.

Moreover, the results show that the likability factor in individuals is more important than the expertise factor from the three scenarios. Based on the results of previous studies, a person's personality can affect the effectiveness of knowledge sharing [27] [28] [29]. One of the goals is to develop new ideas [24]. Therefore, having competence and experience makes people a good friend to share knowledge [24]. Besides, it concluded that the better was organizational levels' value, and the smaller was the influence of the individual level. The three scenarios' findings show some differences in the parameters at the organizational and different levels. Manufacturers, as an organization, must provide support in terms of policies related to the knowledge sharing the culture of their employees. If no policy-related, no matter how good the supplier's ability to share knowledge. Furthermore, if a new manufacturer starts to prioritize policies to familiarize his employees with a knowledge-sharing culture, then it is better to choose individual 
suppliers who are fun and open (high likability). Therefore, it is easy to share knowledge with manufacturer employees.

\section{Conclusion}

This study simulates the effect of individual and organizational character in increasing trust between organizations and knowledge sharing using a multi-agent approach. This study shows that the likability factor is an essential factor in increasing knowledge sharing between organizations. Based on these results, an individual is likely to share his knowledge when interacting with individuals. Therefore, an individual who represents the company in collaboration should be prioritized a delightful personality. Furthermore, the results obtained in this study are the role of different individual characteristics depending on company conditions. In companies that have not yet implemented a knowledge-sharing culture, likability has a crucial role in increasing the knowledge-sharing process between companies. Companies with knowledge-sharing and individual characteristics did not have to play a significant role in sharing knowledge between companies. For further research, it is better to develop conceptual models of knowledge sharing between organizations. Subsequent studies consider the mechanisms and media sharing of knowledge as the factors that influence the success of knowledge sharing. Besides, further research can consider feedback effects on the success of knowledge sharing in previous interactions that affect the characteristics of the individual or organization within the next interaction.

\section{References}

[1] H. H. Azwir and E. B. Pasaribu, "Pemilihan Supplier Menggunakan Metode Analytic Network Process Di PT UTPE," Jurnal Teknik Industri, vol. 18, pp. 103 112, 2017. https://doi.org/10.22219/JTIUMM.Vol18.No2.103-112.

[2] W. Khoiro, "'Evaluasi Supplier Bahan Baku Plat Besi Dengan Menggunakan Metode Analytical Hierarchy Process dan Taguchi Loss Function"(Studi Kasus pada PT. Lamongan Marine Industry)," University of Muhammadiyah Malang, 2015.

[3] M. Le Pennec and E. Raufflet, "Value creation in inter-organizational collaboration: An empirical study," Journal of Business Ethics, vol. 148, pp. 817834, 2018. https://doi.org/10.1007/s10551-015-3012-7.

[4] M. Cao and Q. Zhang, "Supply chain collaboration: Impact on collaborative advantage and firm performance," Journal of operations management, vol. 29, pp. 163-180, 2011. https://doi.org/10.1016/j.jom.2010.12.008.

[5] B. Lawson, K. J. Petersen, P. D. Cousins, and R. B. Handfield, "Knowledge sharing in interorganizational product development teams: The effect of formal and informal socialization mechanisms," Journal of Product Innovation Management, vol. 26, pp. 156-172, 2009. https://doi.org/10.1111/j.15405885.2009.00343.x.

[6] J.-H. Cheng and Y.-C. Fu, "Inter-organizational relationships and knowledge sharing through the relationship and institutional orientations in supply chains," International Journal of Information Management, vol. 33, pp. 473-484, 2013. https://doi.org/10.1016/j.ijinfomgt.2013.01.002.

[7] Y.-H. Chen, T.-P. Lin, and D. C. Yen, "How to facilitate inter-organizational knowledge sharing: The impact of trust," Information \& Management, vol. 51, pp. 568-578, 2014. https://doi.org/10.1016/j.im.2014.03.007. 
[8] M. Ibrahim, "Interorganizational Trust and Interorganizational System's Information Quality," in ICIQ, 2005.

[9] F. Ramadhan and T. Samadhi, "Inter-organizational trust and knowledge sharing model between manufacturer and supplier in the automotive industry," in 2016 IEEE International Conference on Industrial Engineering and Engineering Management (IEEM), 2016, 856-860. https://doi.org/10.1109/IEEM.2016.7797998.

[10] F. Ramadhan, A. F. Rizana, R. Rispianda, and Y. Yuniati, "Kesuksesan Knowledge Transfer Di Laboratorium Perguruan Tinggi Melalui Pengelompokan Rekan Kerja Menggunakan Agent-Based Modeling And Simulation," Jurnal $\begin{array}{llllll}\text { Teknik Industri, } & \text { vol. } & 19, & \text { pp. } & 205-219, & \end{array}$ https://doi.org/10.22219/JTIUMM.Vol19.No2.205-219.

[11] F. Ramadhan, R. Soesanto, A. Rizana, A. Kurniawati, and I. Wiratmadja, "Mechanisms for effective tacit knowledge transfer in university laboratory: An agent-based approach," in 2017 IEEE International Conference on Industrial Engineering and Engineering Management (IEEM), 2017, pp. 1138-1142. https://doi.org/10.1109/IEEM.2017.8290070.

[12] F. Ramadhan, A. Rizana, R. P. Soesanto, A. Kurniawati, and I. I. Wiratmadja, "An Application of Agent-based Modeling and Simulation in Tacit Knowledge Transfer Effectiveness and Individual Performance through the Consideration of Feedback Mechanism," in 2018 IEEE International Conference on Industrial Engineering and Engineering Management (IEEM), 2018, pp. 346-350. https://doi.org/10.1109/IEEM.2018.8607549.

[13] J.-H. Cheng, C.-H. Yeh, and C.-W. Tu, "Trust and knowledge sharing in green supply chains," Supply Chain Management: An International Journal, vol. 13, pp. 283-295, 2008. https://doi.org/10.1108/13598540810882170.

[14] A. Brinkhoff, Ö. Özer, and G. Sargut, "All you need is trust? An examination of inter-organizational supply chain projects," Production and operations management, vol. 24, pp. 181-200, 2015. https://doi.org/10.1111/poms.12234.

[15] T. Das, "Strategic alliance temporalities and partner opportunism," British Journal of Management, vol. 17, pp. 1-21, 2006. https://doi.org/10.1111/j.14678551.2006.00482.x.

[16] K. H. Wathne and J. B. Heide, "Opportunism in interfirm relationships: Forms, outcomes, and solutions," Journal of marketing, vol. 64, pp. 36-51, 2000. https://doi.org/10.1509/jmkg.64.4.36.18070.

[17] B. Ashnai, S. C. Henneberg, P. Naudé, and A. Francescucci, "Inter-personal and inter-organizational trust in business relationships: An attitude-behavioroutcome model," Industrial Marketing Management, vol. 52, pp. 128-139, 2016. https://doi.org/10.1016/j.indmarman.2015.05.020.

[18] W. Rutten, J. Blaas-Franken, and H. Martin, "The impact of (low) trust on knowledge sharing," Journal of knowledge management, vol. 20, pp. 199-214, 2016. https://doi.org/10.1108/JKM-10-2015-0391.

[19] S. Knox, P. Meier, J. Yoon, and J. J. Harou, "A python framework for multi-agent simulation of networked resource systems," Environmental Modelling \& Software, vol. 103, pp. 16-28, 2018. https://doi.org/10.1016/j.envsoft.2018.01.019.

[20] A. Bhaskar, M. Cools, and E. Chung, "An investigation of timed transfer coordination using event-based multi agent simulation," Transportation Research Part C: Emerging Technologies, vol. 81, pp. 363-378, 2017. https://doi.org/10.1016/j.trc.2017.02.018. 
[21] X. Meng, Z. Wen, and Y. Qian, "Multi-agent based simulation for household solid waste recycling behavior," Resources, Conservation and Recycling, vol. 128, pp. 535-545, 2018. https://doi.org/10.1016/j.resconrec.2016.09.033.

[22] H. Takahashi, N. Nishino, and T. Takenaka, "Multi-agent simulation for the manufacturer's decision making in sharing markets," Procedia CIRP, vol. 67, pp. 546-551, 2018. https://doi.org/10.1016/j.procir.2017.12.258.

[23] S. Kim and H. Lee, "The impact of organizational context and information technology on employee knowledge-sharing capabilities," Public administration review, vol. 66, pp. 370-385, 2006. https://doi.org/10.1111/j.15406210.2006.00595.x.

[24] X. Zhang and J. Y. Jiang, "With whom shall I share my knowledge? A recipient perspective of knowledge sharing," Journal of Knowledge Management, vol. 19, pp. 277-295, 2015. https://doi.org/10.1108/JKM-05-2014-0184.

[25] J.-C. Lee, Y.-C. Shiue, and C.-Y. Chen, "Examining the impacts of organizational culture and top management support of knowledge sharing on the success of software process improvement," Computers in Human Behavior, vol. 54, pp. 462474, 2016. https://doi.org/10.1016/j.chb.2015.08.030.

[26] W.-J. Chang, S.-H. Liao, and T.-T. Wu, "Relationships among organizational culture, knowledge sharing, and innovation capability: a case of the automobile industry in Taiwan," Knowledge Management Research \& Practice, vol. 15, pp. 471-490, 2017. https://doi.org/10.1057/s41275-016-0042-6.

[27] T. Pei-Lee, C. Y. Chen, W. C. Chin, and Y. Y. Siew, "Do the Big Five Personality Factors affect knowledge sharing behaviour? A study of Malaysian universities," Malaysian Journal of Library \& Information Science, vol. 16, pp. 47-62, 2017.

[28] A. Kurniawati, T. Samadhi, I. I. Wiratmadja, and R. P. Soesanto, "The Impact of Source, Recipient, and Tacit Knowledge Characteristics on Tacit Knowledge Transfer Effectiveness," in Proceedings of the Asia Pasific Industrial Engineering \& Management System 2016, 2016.

[29] L. N. Marouf and O. E. Khalil, "The influence of individual characteristics on knowledge sharing practices, enablers, and barriers in a project management context," International Journal of Knowledge Management (IJKM), vol. 11, pp. 127, 2015. https://doi.org/10.4018/IJKM.2015010101. 